\title{
Analysis of Physico-Mechanical Properties of Jute and Polyester Blended Yarn
}

\author{
Tanvir Mahady Dip, Prof. Dr. Hosne Ara Begum, Md. Abdullah Al Hossain, Md. Mazbah Uddin, \\ Md. Omar Faruque \\ 1,2,3,4,5 Bangladesh University of Textiles
}

\begin{abstract}
The cardinal objective of blending is to combine fibers which emphasizes good quality and minimizes poor quality. Jute is a natural fiber popularly known as the golden fiber of Bangladesh. It is one of the cheapest and strongest natural fibers and is considered the fiber for the future. Polyester is a manufactured product which tends to be very resilient, quick drying, resistant to biological damage such as mold and mildew, easy to wash and able to hold forms well. Although polyester is often maligned as a textile, it has many useful applications. The following study is an experimental research on how blending of Polyester with Jute behaves a single yarn manufactured using jute yarn manufacturing machineries. Tossa Jute of B grade and Polyester of 1.4 Denier \& $32 \mathrm{~mm}$ staple length were chosen for the blending. The blending was performed at the $2^{\text {nd }}$ Draw Frame stage of jute manufacturing system and blending ratio of jute and polyester fibers is 80:20. Count of Jute blended sliver and yarn after each stage was measured and recorded. The present work is concerned with the investigation of physical properties of manufactured jute blended yarns. Tests were conducted on blended yarn to find out Count, Twist per Inch (TPI), Strength, Quality Ratio Moisture Regain, Moisture Content, Hairiness, Percentage of Fibers in the final blended yarn etc.
\end{abstract}

Keywords : Blended Yarn, Blended Properties, Improved Characteristics, Jute Spinning Machineries and testing equipment, Natural and Manmade Fibers, Yarn Testing Equipment and Functions etc.

\section{Introduction}

Blending of fibers is the process of mixing two or more entirely different kinds of fibers together to form yarn of unique properties. Blending is accomplished before spinning and is performed to impart such desirable properties such as strength or durability, to reduce cost by combining expensive fibers with less costly types or to achieve a special color of texture effects (Encyclopedia Britannica). The variety of natural and manmade fibers available today enables us a wide selection of fibers to use. As we know all the fibers have some good, fair and poor characteristics, the blending of fibers is done with the sole interest of exploiting the desired characteristics of the fibers in the yarn along with improving the weaker ones. Apart from these reasons, blending is also done to execute some secondary motive like to produce cross dyed effects by combining fibers with unlike dye affinity, to improve spinning, weaving and finishing efficiency etc.

Jute is a natural bast fiber of vegetable origin. It is known as the golden fiber of Bangladesh not only because of its shiny, lustrous and gold like appearance but also due to its ample availability as well as its cheap rates. Bangladeshi weather is extremely conducive for growing jute fiber. The cardinal advantage of jute fiber is that it is $100 \%$ bio degradable and environment friendly.

Jute fibers contain favorable characteristics like its high tensile strength, good moisture regain percentage, better breathability, antistatic and insulating property etc. that makes them auspicious to be used in manufacturing textile products. But characteristics like low crease resistance, low drapability, losing 
strength significantly when wetted, creating shade effect and becoming yellowish in presence of sunlight hinders jute's effectiveness.

According to Federal Trade Commission Definition, Polyester is a manufactured fiber in which the fiber forming substance is any long chain synthetic polymer composed of at least $85 \%$ by weight of an ester of a substituted aromatic carboxylic acid, including but not restricted to substituted terephthalic units, $\mathrm{p}(-\mathrm{R}-\mathrm{O}-$ $\mathrm{CO}-\mathrm{C} 6 \mathrm{H} 4-\mathrm{CO}-\mathrm{O}-) \mathrm{x}$ and para substituted hydroxyl-benzoate units, $\mathrm{p}(-\mathrm{R}-\mathrm{O}-\mathrm{CO}-\mathrm{C} 6 \mathrm{H} 4-\mathrm{O}-) \mathrm{x}$. Polyester fibers have many advantages, like they are strong, resilient and resistant to stretching, shrinking, most chemicals, wrinkle, mildew and abrasion. It has got disadvantages like low absorbency, static and pilling problems. They are not bio degradable and particularly ecofriendly.

The purpose of the blending that this study is concerned with is that to utilize the beneficial properties that these two poses and to alleviate their weaknesses that may cause problems in the further processing.

\section{Literature Review}

\subsection{Background of the Study:}

Various researchers have tried blending of jute with different fibers in order to achieve the best utilization of the positive attributes of jute fiber and to reduce its negative attributes as far as practicable. Blending also makes the fabric manufacturing process economical. As blend of polyester / viscose jute blend with cotton provide crease recovery, dimensional stability, tensile strength, abrasion resistance, moisture absorption and drapability (Choudhary 2006). Similarly, Mann et al. (1998) did a study on jute/acrylic fibers blended yarns with different ratio of fibers, 100/0, 10/90; 20/80, 30/70, 40/60, 50/50. Polyester is known for its wrinkle - free appearance and easy care. The strength, durability, abrasion resistance, wrinkle resistance shape and size retention of these blended fabrics increase due to polyester (Coabman 1983). Similarly, Padam et al. (1994) concluded that blending silk with polyester and acrylic it reduce the cost and also increase the durability.

\subsection{Objectives of the study:}

The basic objective of this study is to find out whether the end product produced shows better results in case of physical properties than when they are used individually or separately. There are some other important objectives. They are given below:

- To bring out the best of the both fiber properties in the end product.

- To reduce the weak properties of the both fibers as much as possible.

- To examine whether we can compensate the variation of properties in fibers.

- To hold down the cost of raw materials as much as possible by blending a relatively cheap fiber (Jute in this case) with a comparatively expensive one (Polyester in this case).

\subsection{Significance of the study:}

The study is significance in the sense that it enables us to explore another area for jute which is available in ample in our countries. On the other hand Man Made Synthetic fibers are not only expensive but also they cannot provide some important properties which can only be found in the natural fibers. By mixing Jute with polyester we can reduce the amount of Polyester as raw material and can save a lot of money. Also, the end product becomes enriched as it exposes some of the natural properties. This study facilitates a way for the possibility of using Jute in combination with Polyester and to achieve the above mentioned properties in the end product.

\section{4: Scope of the study:}

As no fiber is perfect, one way or another they tend show some characteristics which is neither convenient nor desirable for further application. So the practice of blending different fibers together in order to mitigate the undesirable characteristics as much as possible is being carried out worldwide. A tendency of blending a natural fiber with a synthetic fiber is very common as we have the possibility of getting the best characteristics out of both the fibers. Moreover, a mixing of natural fiber with synthetic fiber tend to reduce 
the price of raw materials by a considerable amount which really helps to bring down production cost by a great margin as we know the raw material price accounts for about $50 \%$ to $70 \%$ of total production cost. So the scope of conducting these types of experiments is great as it shows immense potentiality.

\subsection{Raw Materials}

\subsubsection{Jute Anatomy:}

The jute fibers lie within the stem of the plant just beneath the bark and surrounded by soft tissue. The following figure shows diagrammatically what would be seen if a V-shaped wedge were Cut out of a jute stem.

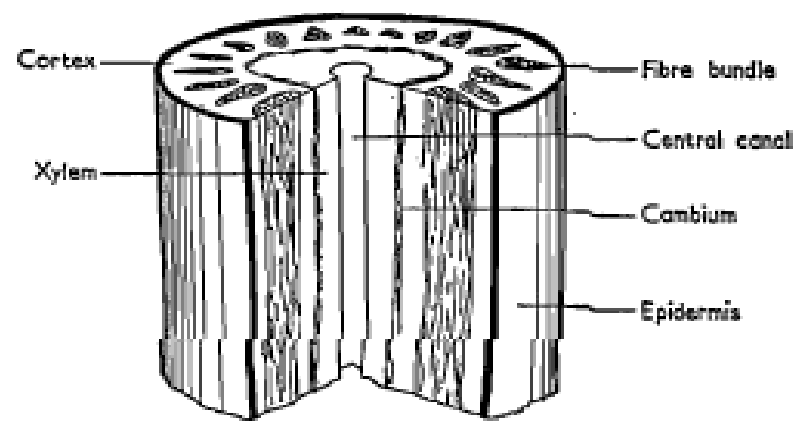

Figure 2.1: Anatomy of Jute Fiber

On the outside of the stem is the epidermis which in young plants is green and soft but becomes harder, particularly at the root end, as the plant matures. Immediately beneath the epidermis lies the cortex, imbedded in which are the fiber bundles. Continuing to move inwards to the axis of the stem the cambium is found, a continuous layer. On the inside of the cambium lies the xylem which, as the plant matures, becomes more and more woody and finally, running down the center of the stem is a canal which in mature $\mathbf{C}$. Olitorius stems is usually hollow but in C. capsularis stems still contains soft pith. The cambium plays an extremely important part in the life of the plant and is particularly interesting because from it that the fiber bundles develop.

\subsubsection{Polyester}

Polyester fibers are sometimes spun together with natural fibers to produce a cloth with blended properties. Cotton-polyester blends (poly cotton) can be strong, wrinkle and tear-resistant, and reduce shrinking.

There may be ways to use Polyester fiber blending with other natural fiber like jute using alternative manufacturing techniques. Synthetic fibers using polyester have high water, wind and environmental resistance compared to plant-derived fibers.

Polyesters are synthesized by the application of polycondensation reaction. Hence the polymer of polyester is a condensation polymer. Such polymers are created through the joining of molecules with the elimination of by product such as water $\left(\mathrm{H}_{2} \mathrm{O}\right)$. Polyester polymer contains ester functional group in their main chain.

The general equation for the reaction of a di-ol with a di-acid is:

$$
(\mathrm{n}+1) \mathrm{R}(\mathrm{OH})_{2}+\mathrm{n} \mathrm{R}^{\prime}(\mathrm{COOH})_{2} \rightarrow \mathrm{HO}\left[\mathrm{ROOCR}^{\prime} \mathrm{COO}\right]_{\mathrm{n}} \mathrm{ROH}+2 \mathrm{n} \mathrm{H}_{2} \mathrm{O}
$$

For example, polycondensation reaction of Polyethylene terephthalate polyester also known as Dacron or Terylene is: 
Ethylene Glycol Terephthalic Acid

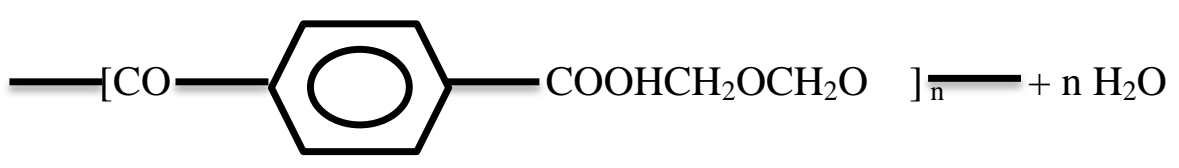

PET (Polyethylene Terephthalate)

\subsection{Processes:}

\subsubsection{Emulsification:}

If the jute fiber is taken from the bale and passed directly over the spinning machinery, then the yarn which is made from it is weak and irregular and the amount of waste in processing is high. In order to produce an acceptable yarn it has been customary from the earliest days of jute manufacture on an industrial scale to condition the fiber for spinning by adding oil and water to it-this operation is known as batching. The water softens the fiber and increases its extensibility, both of which factors prevent excessive fiber breakage at the cards, make it easier for the fiber to bend round pins and rollers, and reduce waste losses. The percentage of oil has significant strength on jute yarns. The exact nature of the part played by the oil is not fully understood but it is thought to have an important role in giving cohesion to the slivers, helping them to be drafted properly at the later stages. Originally, the oil and water were added separately but now they are, almost invariably, added simultaneously as an emulsion.

\subsubsection{Carding}

The primary function of carding is to individualize the fibers and convert the jute into a uniform supply of fibrous material that can be drafted and then twisted into yarn. Normally in jute processing both breaker card and finisher card machines are used but in our experiment we have used breaker card two times.

\subsubsection{Draw Frame}

Drawing is the process to make card sliver more thinly suitable for subsequent processes. The main purpose of drawing is to straighten the fibers and laying them along the sliver axis so that when they come to be spun on the spinning frame they will be evenly drafted and twisted to form an acceptable yarn. In jute processing normally 3 draw frame passages are used which are $1^{\text {st }}, 2^{\text {nd }}, 3^{\text {rd }}$ draw frame.

\subsubsection{Blending}

Blending of fibers is the process of mixing two or more entirely different kinds of fibers together to form yarn of unique properties.

\section{Advantages of Blending}

- When two different types of fibers are blended, the properties of these two different fibers are synergized. For instance, in the blend of cotton and polyester, cotton provides the absorbency and polyester provides the strength.

- Blending is done to produce a fabric, which is economical by combining the aesthetic comfort properties of the natural fibers with the easy care and strength properties of synthetic fibers.

- Blending also helps to provide the fabric's light weight with all desirable characteristics. Improving spinning, weaving and finishing efficiency and the uniformity of product. 
Methods of Blending:

Blending can be done at the opening stage, drawing etc.

1. In the initial opening stage of the blow room operation, the fibers are spread one on top of the other and fed into the blending feeder.

2. The blending can also be done in the carding stage.

3. Similarly the blending can be done at drawing or roving stage.

4. A filament yarn blended contains yarns of different deniers (denier is the yarn numbering system used for filament yarns) blended together.

\subsubsection{Spinning}

The essential features of the spinning process are drafting, twisting and winding-on a suitable package. In spinning process, slivers are drafted for elongation and then twisted into yarn to impart strength. Jute yarn is produced through sliver spinning method or rove spinning method. For sliver spinning apron draft or slip draft machine present. The crimped sliver from second or third draw frame is fed into one of these machines.

\subsection{Quality Testing Instruments:}

\subsubsection{Wrap Reel:}

A wrap reel or skein winder is a device for measuring yarn length and making it into hanks of a standard size. The tension of the yarn as it was wound onto the reel was important because it would be elastic and so a standard tension was required to ensure uniformity. For a given reel, this would be determined by the friction of the setup and so the test hanks would be made and measured in other ways to calibrate the device. In our experiment the wrap reel we used was hand driven.

\subsubsection{Yarn Strength Tester:}

The Single Yarn Strength Tester used for this experiment has been shown below along with it's specification.

\section{$M / c$ specification:}

The Lea Strength Tester

Goodbrand \& Co. Ltd.

Capacity- 25 lbs.

Principle: CRE (Constant Rate of Elongation)

Testing atmosphere:

Temperature $-29^{\circ} \mathrm{C}$ and relative humidity $-76 \%$

Standard atmosphere: temperature $-20^{\circ} \mathrm{C}$ and relative humidity $-65 \%$.

Sample:

Jute yarn length- 24 inches.

\subsubsection{Electric Balance}

In count measurement electric balance was used to measure weight of desired length of blended yarn

\subsubsection{Ordinary Twist Tester:}

Ordinary Twist Tester is used to measure the number of twist is a specified length of yarn.

\subsubsection{Moisture Regain Tester: Reynolds and Branson "Rapid Regain Tester"}

Apparatus: Sample container with two caps, means for drying (hot air current), electric balance.

Moisture Regain Property: 
When the moisture present in a textile material is calculated as a percentage on the oven-dry weight the percentage is known as the moisture regain (MR). Mathematically MR is calculated as:

$$
\mathrm{MR}=\frac{W}{D} \times 100
$$

\section{Moisture Content Property:}

The amount of moisture in a material when expressed as a percentage of the total weight is known as the percentage moisture content (MC).

Mathematically Calculated as:

$$
\mathrm{MC}=\frac{W}{W+D} \times 100
$$

Where, $\mathrm{D}=$ Oven dry weight

$$
\mathrm{W}=\text { Weight of water }
$$

\section{Research Methodology}

\subsection{Fiber Properties:}

In this experiment we for blending Bangla Tossa B (BTB) jute fibers and polyester fibers were used. Fiber properties of both jute and polyester are pointed in below table:

Table 3.1: Jute \& Polyester fiber properties

\begin{tabular}{|l|l|l|}
\hline Properties & Jute & Polyester \\
\hline Length & $\mathbf{7 . 5 - 8} \mathbf{f t}$. & Vary (32 mm) \\
\hline Tenacity & $\mathbf{3 - 4} \mathbf{g m} / \mathbf{d e n}$ & $\mathbf{5 - 7} \mathbf{g m} / \mathbf{d e n}$ \\
\hline Elongation & $\mathbf{1 . 7 \%}$ & $\mathbf{1 5 - 3 0 \%}$ \\
\hline Moisture regain & $\mathbf{1 3 . 7 5}$ & $\mathbf{0 . 4 \%}$ \\
\hline Specific gravity & $\mathbf{1 . 5}$ & $\mathbf{1 . 3 8}$ \\
\hline Chemical Composition & $\begin{array}{l}\text { Cellulose, hemicellulose, } \\
\text { lignin }\end{array}$ & $\begin{array}{l}\text { Ethylene Glycol \& } \\
\text { Terephthalic acid }\end{array}$ \\
\hline Dissolve & Concentrated Acid Solution & $\begin{array}{l}\text { Phenol in hot state and } \\
\text { pigments }\end{array}$ \\
\hline Dye & Basic & \begin{tabular}{l} 
Disperse azoic and \\
\hline
\end{tabular} \\
\hline
\end{tabular}

\subsection{Process Flow of Blended Yarn Manufacturing:}



Fiber

Openinng

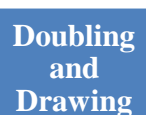

Drawing
Final

Polyester

Sliver

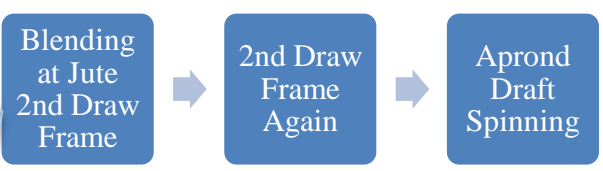


Figure 3.1: Process flow of Jute Polyester Blended Yarn Manufacturing

\subsection{Brief Description of the total procedure:}

The whole experiment was carried out in "Bangladesh University of Textiles" Spinning Lab, Jute Lab and Testing Lab.

The whole procedure was divided into three main phases:

1. Polyester Sliver Preparation from raw unopened Polyester.

2. Jute sliver preparation from raw Jute \&

3. Blended Yarn manufactured using Jute Spinning Machineries.

In the first stage raw unopened Polyester Fiber was collected and manually opened. Then they were converted into minilap using miniature carding machine. The lap was turned into polyester sliver by using miniature draw frame. 6 single slivers were subjected to doubling process to produce a more uniform sliver.

In the second stage, raw Jute fiber was collected and emulsified using water-glycerin mixture. These were conditioned for 72 hours and subjected to carding in breaker carding machine ( 2 times) and $1^{\text {st }}$ draw frame to produce carded and $1^{\text {st }}$ drawn sliver respectively.

In the third and final stage, the Polyester sliver and $1^{\text {st }}$ drawn Jute sliver were blended together in the $2^{\text {nd }}$ draw frame in the ratio of 20:80 (Polyester: Jute) based on weight. This process was repeated a second time to achieve more uniform distribution of Polyester over Jute. The $2^{\text {nd }}$ drawn sliver was subjected to spinning in Apron draft sliver spinning machine to get the desired yarn.

\section{Experiment}

\subsection{Polyester Preparation}

\subsubsection{Polyester Lap Preparation:}

For polyester preparation polyester fibers were collected from bale. Then polyester fibers were manually by hand. After that, a miniature (SDL, England) carding machine was used to make several laps. In this processing 35 grams of polyester was used in each lap. Average lap measurement was approximately (30in $\mathrm{x}$ 10in) Length $x$ Width. Final lap weight was approximately 28 to 32 grams.

\subsection{2: Polyester Sliver Preparation:}

Lap from miniature carding machine was processed to make polyester sliver. From each lap a single sliver was produced by using a miniature draw frame machine with 4 over 4 drafting system. Such 6 single slivers were doubled to produce the final polyester sliver. This final sliver was directly used for blending with jute sliver.

The miniature draw frame (SDL, England) was used to produce sliver. The gauges from nip to nip of each section (Back, Middle and Front) are shown below.

Table 4.1 Drafting Zone Gauge

\begin{tabular}{|c|c|}
\hline Drafting Zone & Gauge (Inches) \\
\hline Back Zone & 1.5 \\
\hline Middle Zone & 2 \\
\hline Front Zone & 2 \\
\hline
\end{tabular}

\subsection{Jute Preparation}

\subsubsection{Jute Fiber Emulsification:}


Jute of grade-B was emulsified to make it softer and give moisture to fibers. We have used $10 \mathrm{kgs}$ of jute fibers with $20 \%$ emulsion on weight of jute. The following mixture was used as Emulsion:

Table 4.2: Emulsion Recipe

\begin{tabular}{|l|l|}
\hline Constituent & Amount (grams) \\
\hline Water & 1800 \\
\hline Glycerin & 200 \\
\hline Total & 2000 \\
\hline
\end{tabular}

Several Morah of jute were made and emulsion was sprayed manually on them. Then, it was conditioned for 72 hours at room temperature.

\subsubsection{Carding Process:}

The breaker carding machine used for the experiment is shown below. The speed of different rollers along machine specification are also given:

\section{Speed of Rollers:}

- Cylinder: 2400 - 2700 feet per minute

- Feed roller: 9 - 14 feet per minutes

- Worker: 35 - 50 feet per minutes

- Stripper: 300 - 500 feet per minutes

- Doffer: 75 - 95 feet per minutes

- Delivery roller: 150 - 200 feet per minutes

The conditioned jute fibers were fed to the carding machine manually by hand. In card processing the jute fibers are transformed into a thin web of separate fibers emerging as a fleece which is then condensed into a sliver. In this experiment sliver was manufactured by using James Mackie \& Sons Ltd. (Ireland) breaker card machine.

Table 4.3: Breaker Card Specification

\begin{tabular}{|c|c|}
\hline Machine & Breaker Card \\
\hline Draft & 13 \\
\hline Sliver Count & $8 \mathrm{lbs} . / 100$ Yards \\
\hline Dollop Weight & $15-18 \mathrm{lbs}$. \\
\hline Clock Length & 10 Yards \\
\hline
\end{tabular}

\subsubsection{Drawing Process:}

Only $1^{\text {st }}$ and $2^{\text {nd }}$ draw frame were used. And $2^{\text {nd }}$ draw frame was used for two times. First time for jute sliver processing and second time for jute and polyester sliver blending. $3^{\text {rd }}$ draw frame was skipped due to low strength of blended sliver. $1^{\text {st }}$ and $2^{\text {nd }}$ draw frame have a doubling of 2:1 and 3:1 respectively. James Mackie $\&$ Sons Ltd. (Ireland) draw frames were used to produce the slivers.

Comparative Specifications of $1^{\text {st }}$ and $2^{\text {nd }}$ Draw Frames:

Table 4.4: Comparative Specification of $1^{\text {st }}$ and $2^{\text {nd }}$ Draw frame

\begin{tabular}{|l|l|l|}
\hline Parameters & $1^{\text {st }}$ Draw Frame & $2^{\text {nd }}$ Draw Frame \\
\hline Feed & Card Sliver & Drawn Sliver \\
\hline Doubling & At delivery & At Delivery \\
\hline Crimping & No & Yes at delivery \\
\hline Can & No & Yes \\
\hline Doubling & $\mathbf{2 : 1}$ & $\mathbf{3 : 1}$ \\
\hline
\end{tabular}




\begin{tabular}{|l|l|l|}
\hline Sliver Feed/Head & $\mathbf{4}$ & $\mathbf{6}$ \\
\hline Delivery/Head & $\mathbf{2}$ & $\mathbf{2}$ \\
\hline No. of Head & $\mathbf{2}$ & $\mathbf{3}$ \\
\hline Draft & $\mathbf{3 - 5}$ & $\mathbf{5 - 7}$ \\
\hline Faller Bar & Push Bar & Spiral Screw \\
\hline Back Retaining Roller Dia & $\mathbf{2 . 2 5}$ inch & $\mathbf{2}$ inch \\
\hline Delivery roller Dia & $\mathbf{3 . 5}$ inch & $\mathbf{3 . 2 5}$ inch \\
\hline
\end{tabular}

Machine Parameters are given below:

Table 4.5: Machine Parameter of $1^{\text {st }} \& 2^{\text {nd }}$ Draw Frame

\begin{tabular}{|l|l|l|}
\hline Machine Name & First Draw Frame & Second Draw Frame \\
\hline Reach & $\mathbf{1 3}$ inch & $\mathbf{1 2}$ inch \\
\hline Pitch & $\mathbf{0 . 5}$ inch & $\mathbf{0 . 5}$ inch \\
\hline Nip & $\mathbf{2 . 0}$ inch & $\mathbf{2 . 0}$ inch \\
\hline
\end{tabular}

\subsubsection{Blending Process:}

Sliver blending process was used. Sliver of polyester and jute were blended at $2^{\text {nd }}$ draw frame passage of jute spinning system. The ratio of 20:80 of polyester: Jute was used. Though a ratio of 10:90 of Polyester: Jute was also tried. But 20:80 ratio was successful.

Polyester

Sliver

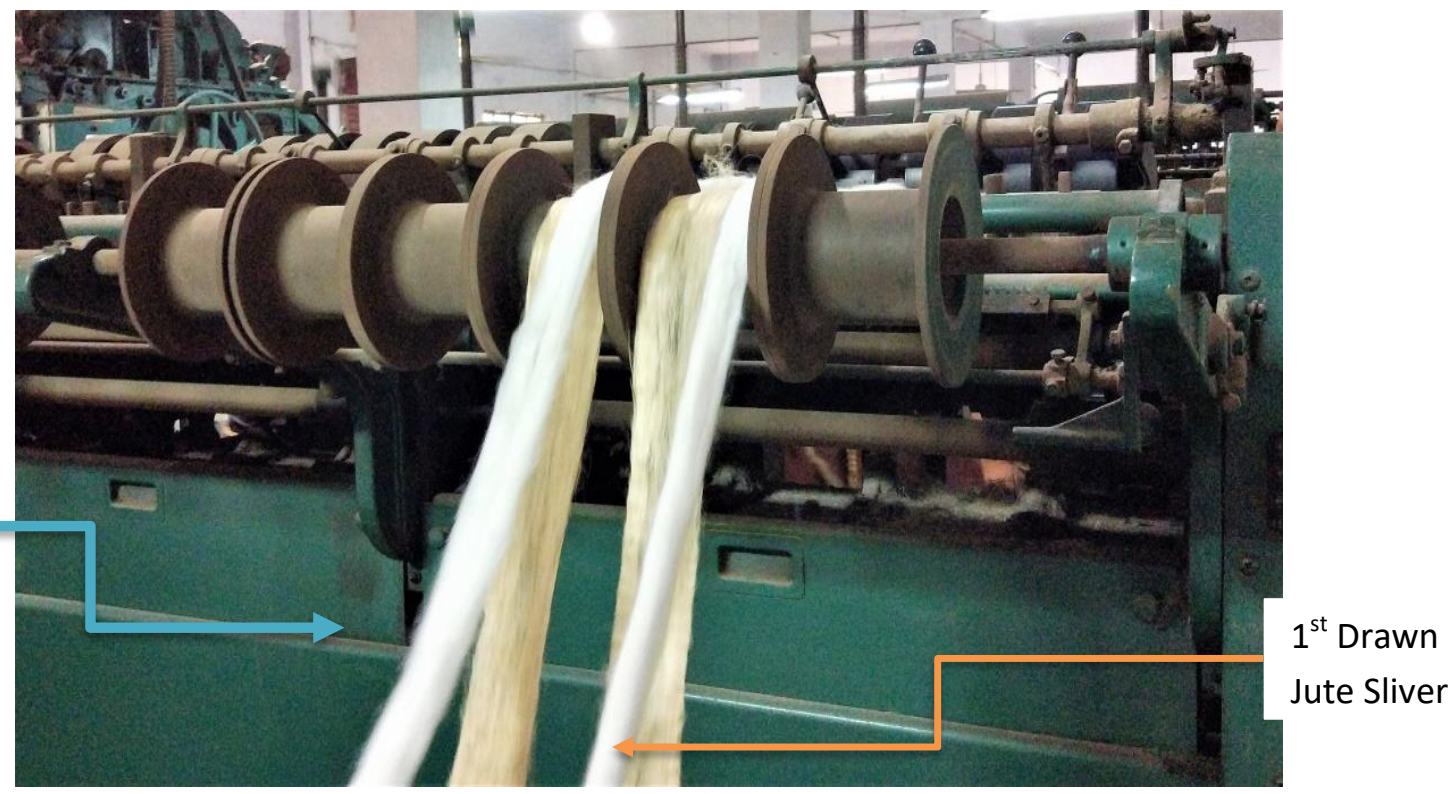

Figure 4.9: Blending of Jute with Polyester in $2^{\text {nd }}$ Draw Frame

\subsubsection{Spinning Process:}

In this experiment, Apron Draft Sliver Spinning Machine was used to produce yarn which is manufactured by James and Mackie \& Sons Ltd. The underlying principle is feeding draw frame sliver to the drafting zone of the spinning machine. The sliver is drafted to significant amount producing a suitable strand capable of getting twist by the flyer and then winding onto a suitable parallel wounded package.








Figure 4.13: Final Yarn Package

\section{Result And Discussion}

\subsection{Count at different stages of manufacturing:}

The following counts at different stages of manufacturing of Jute-Polyester blend were calculated.

Table 5.1: Sliver Count of Polyester, Jute \& Blend at different stages

\begin{tabular}{|c|c|c|}
\hline Product at different stages & Polyester Sliver (Fineness) & Jute Sliver (Fineness) \\
\hline Drawn Sliver (PES) & 2.4 Ktex or 0.25Ne & - \\
\hline Carded Sliver (Jute) & - & $8 \mathrm{lbs} / 100$ yards \\
\hline $1^{\text {st }}$ Drawn Sliver (Jute) & - & $2.12 \mathrm{lbs} / 100$ yards \\
\hline \multicolumn{2}{|c|}{$0.68 \mathrm{lbs} / 100$ yards } \\
\hline $2^{\text {nd }}$ Drawn Sliver (Blend) & Blending \\
\hline Yarn (Blend) & $7.5 \mathrm{lbs} /$ Spyndle \\
\hline
\end{tabular}

\subsection{View of Blend Sliver}

The enlarged view of the blend sliver is shown below. We can see white polyester fibers are visible into golden jute fibers.
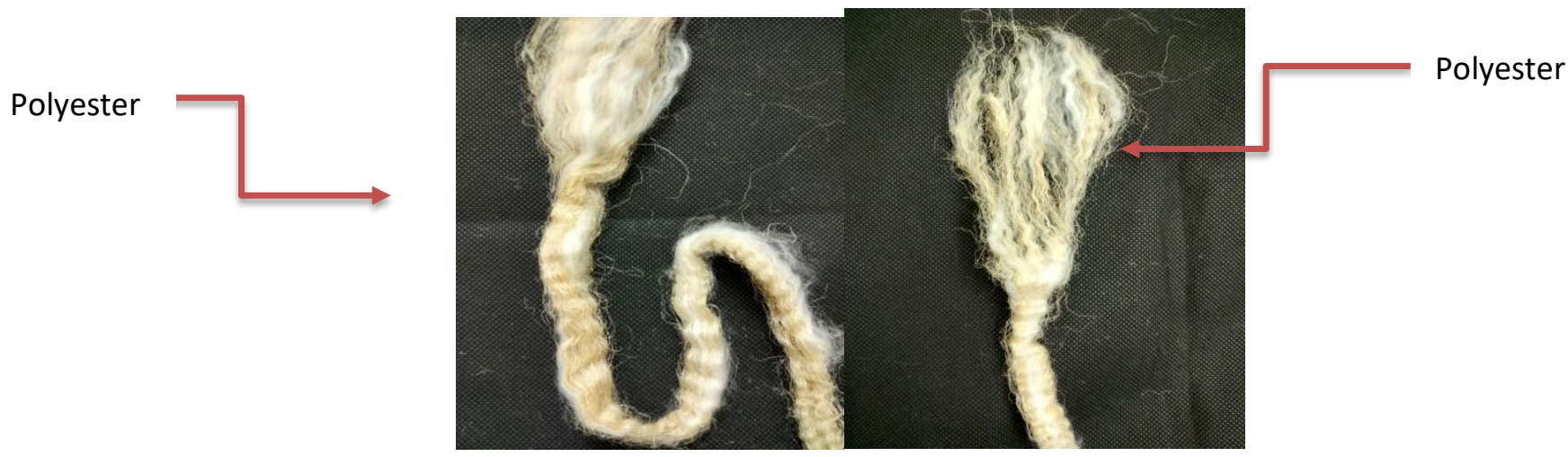

Figure 5.1: Jute \& Polyester Blended Sliver

\subsection{Blend yarn properties:}

The expectation was to produce a blend yarn of count 7.5-8 lbs/Spyndle with TPI is between 5-6 according to the existing machine setting and to have significant amount of strength in the final blend yarn. 
5.3.1 Count: Count of resultant blended yarn was calculated in lbs/ Spyndle unit by using Jute Wrap Reel \& Electric Balance. 5 readings of Weight of specified length of yarn ( 25 yards) were taken and the average value was calculated. Standard Deviation and Coefficient of Variance were also calculated.

Table 5.2: Yarn Count (lbs/Spyndle)

\begin{tabular}{|c|c|}
\hline Observations & Count (lbs/Spyndle) \\
\hline Sample 1 & $\mathbf{7 . 5}$ \\
\hline Sample 2 & $\mathbf{6 . 7}$ \\
\hline Sample 3 & $\mathbf{8 . 4}$ \\
\hline Sample 4 & $\mathbf{8 . 3}$ \\
\hline Sample 5 & $\mathbf{6 . 6}$ \\
\hline Mean Count & $\mathbf{7 . 5}$ \\
\hline Standard Deviation & $\mathbf{0 . 7 6}$ \\
\hline Coefficient of Variance & $\mathbf{1 0 . 1 5 \%}$ \\
\hline
\end{tabular}

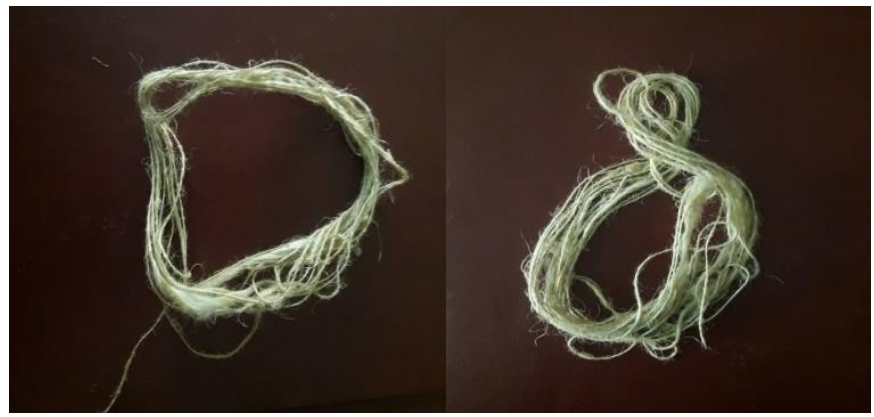

Figure 5.2: A skein of final blend yarn

5.3.2 Twist per Inch (TPI): Twist at a specified length (inch) was determined by using the ordinary twist tester in the quality testing lab. 5 readings of Twist per 10 inches of 5 different samples from 5 different places were taken the average value was calculated. Standard Deviation and Coefficient of Variance were also calculated.

Table 5.4: Yarn Twist per Inch (TPI)

\begin{tabular}{|c|c|}
\hline Observations & Twist Per Inch (TPI) \\
\hline Sample 1 & $\mathbf{6 . 2}$ \\
\hline Sample 2 & $\mathbf{6 . 7}$ \\
\hline Sample 3 & $\mathbf{5 . 6}$ \\
\hline Sample 4 & $\mathbf{6 . 8}$ \\
\hline Sample 5 & $\mathbf{6 . 5}$ \\
\hline Mean TPI & $\mathbf{6 . 4}$ \\
\hline Standard Deviation & $\mathbf{0 . 4 3}$ \\
\hline Coefficient of Variance & $\mathbf{6 . 7 7 \%}$ \\
\hline
\end{tabular}

5.3.3 Single Yarn Strength: Single yarn strength was determined by using single yarn tester in the quality testing lab. 5 readings of breaking load in lbs. unit of 5 different samples from 5 different places were taken and the average value was calculated. Standard Deviation and Coefficient of Variance were also calculated.

Table 5.3: Single Yarn Strength

\begin{tabular}{|c|c|}
\hline Observations & Strength (lbs.) \\
\hline Sample 1 & $\mathbf{5 . 4}$ \\
\hline Sample 2 & $\mathbf{4 . 3}$ \\
\hline
\end{tabular}




\begin{tabular}{|c|c|}
\hline Sample 3 & $\mathbf{5 . 7}$ \\
\hline Sample 4 & $\mathbf{5 . 0}$ \\
\hline Sample 5 & $\mathbf{5 . 6}$ \\
\hline Mean Strength & $\mathbf{5 . 2}$ \\
\hline Standard Deviation & $\mathbf{0 . 5 1}$ \\
\hline Coefficient of Variance & $\mathbf{9 . 8 0 5 \%}$ \\
\hline
\end{tabular}

\subsubsection{Yarn Quality Ratio (QR):}

Jute yarn quality ratio is defined as the ratio of yarn strength in lbs to yarn count in $\mathrm{lbs} /$ Spyndle expressed as percentage.

Table 5.4: Quality Ratio of Blend Yarn

\begin{tabular}{|c|c|c|c|}
\hline Sample No. & Count (lbs/Spyndle) & Strength (lbs) & QR \\
\hline 1 & $\mathbf{7 . 5}$ & $\mathbf{5 . 4}$ & $\mathbf{7 2 \%}$ \\
\hline 2 & $\mathbf{6 . 7}$ & $\mathbf{4 . 3}$ & $\mathbf{6 4 . 2 \%}$ \\
\hline 3 & $\mathbf{8 . 4}$ & $\mathbf{5 . 7}$ & $\mathbf{6 7 . 6 \%}$ \\
\hline 4 & $\mathbf{8 . 3}$ & $\mathbf{5 . 0}$ & $\mathbf{6 0 . 2 4 \%}$ \\
\hline 5 & $\mathbf{6 . 6}$ & $\mathbf{5 . 6}$ & $\mathbf{8 4 . 9 \%}$ \\
\hline Avg. & & & $\mathbf{6 9 . 7 8 \%}$ \\
\hline
\end{tabular}

\subsubsection{Moisture Regain and Moisture Content:}

For Moisture Regain and Content taste the Reynold and Brenson "Rapid Regain Tester" was used. A sample of 5 gram yarn was taken and heated in the machine at $105^{\circ} \mathrm{C}$ until the moisture content was completely vaporized. The weight of sample before and after heating was recorded and Moisture Content and Regain was determined in percentage.

Sample weight $=5 \mathrm{gm}$

Weight of the sample container $=63.05$ grams

Time of each drying cycle $=1 \mathrm{~min}$

Sample Weight (with moisture $)+$ Container Weight $=68.05$ grams $=\mathrm{W}_{\mathrm{s}}$

Table 5.5: Consecutive weight after each drying cycle

\begin{tabular}{|c|c|}
\hline S1. No. & $\mathrm{W}_{\mathrm{s}}(\mathrm{Grams})$ \\
\hline 1 & 67.78 \\
\hline 2 & 67.65 \\
\hline 3 & 67.61 \\
\hline 4 & 67.61 \\
\hline
\end{tabular}

Weight of moisture $=(68.05-67.61)=0.44$ grams

Dry weight $=(5-0.44$ grams $)=4.56$ grams

Table 5.6: Moisture Regain and Content (\%) 


\begin{tabular}{|c|c|}
\hline Moisture Regain (MR) & Moisture Content (MC) \\
\begin{tabular}{c|}
$\frac{\mathbf{0 . 4 4}}{\mathbf{4 . 5 6}} \boldsymbol{x} \mathbf{1 0 0}$ \\
$=9.64 \%$
\end{tabular} & $\frac{\mathbf{0 . 4 4}}{\mathbf{5}} \boldsymbol{x} \mathbf{1 0 0}$ \\
& $=\mathbf{8 . 8 \%}$ \\
\hline
\end{tabular}

Thus, the Moisture Regain and Content $(\%)$ in the resulted blend yarn was determined.

\subsubsection{Percentage of Constituent Fibers:}

Percentage of each constituent fibers in the single yarn was calculated by carrying out chemical test in the quality testing lab.

The weight of specified length of yarn was taken and recorded. Then it was dipped into in a phenol solution. As we know that polyester dissolves in phenol. So the polyester part of the yarn would dissolve after a considerable amount of time. Only the jute part would remain. The rest of the yarn was taken out and dried. Then the yarn was weighted again and recorded. Mathematical equation for fiber percentage calculation in blended yarn:

$$
\text { Percentage of Component }=\frac{\text { Total Wt. of Yarn }- \text { Wt. after disolving and drying }}{\text { Total Wt. of Yarn }} \times 100
$$

From these two data the percentage of Jute and Polyester in the yarn were calculated.

Table 5.7: Percentage of Jute and Polyester in Yarn Strand

\begin{tabular}{|c|c|}
\hline Constituent Fibers & Percentage (average) \\
\hline Jute & $\mathbf{8 3 \%}$ \\
\hline Polyester & $\mathbf{1 7 \%}$ \\
\hline
\end{tabular}

\subsection{Blend yarn faults}

The resulting Blend yarn is not perfect. It shows some faults in its physical structure.

\# The most acute one is slub-like thick places at random intervals. This is due to variation in the length between the participating components. The comparatively shorter polyester fibers cannot cope with the longer jute fibers and the reach and gauge setting in the machine which is suitable for jute.

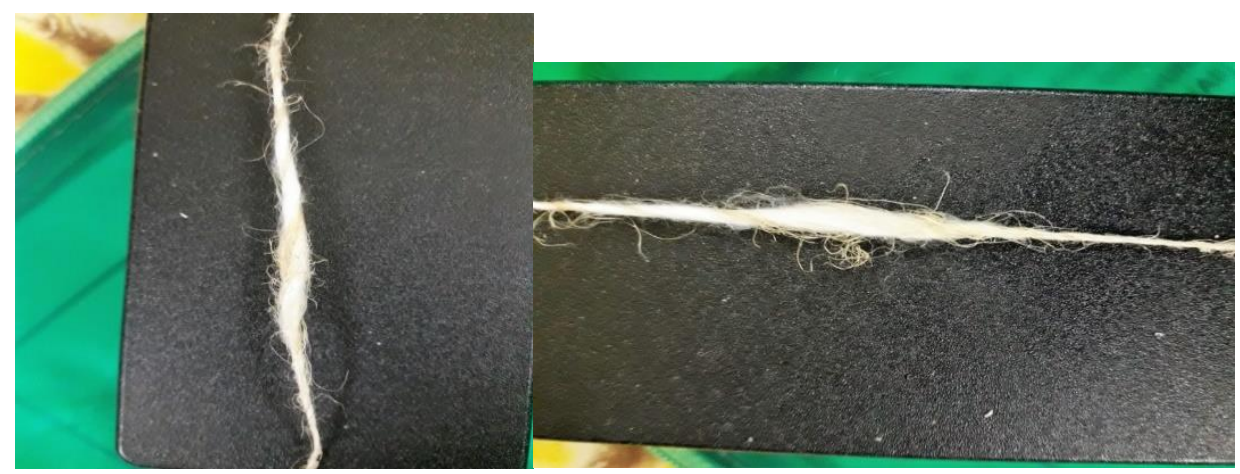

Figure 5.3: Thick Place and Irregular distribution of Polyester Fiber in Blend Yarn

\# We also see the irregularity of Polyester throughout the strand. Sometimes a gathering of polyester fibers can be noticed at random intervals. 
\# Apart from these there are also some thin places which can be seen in random places throughout different parts along the length.

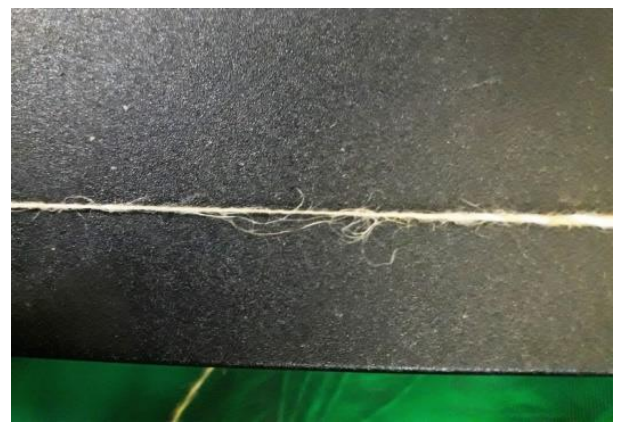

Figure 5.5: Thin Place in Blend Yarn

\# Hairiness: Hairiness is defined as the no. of protruding fibers or total length combining of all the fibers protruding out from the yarn surface in a specified unit of length. The figure shows hairiness of the resulting blend yarn.

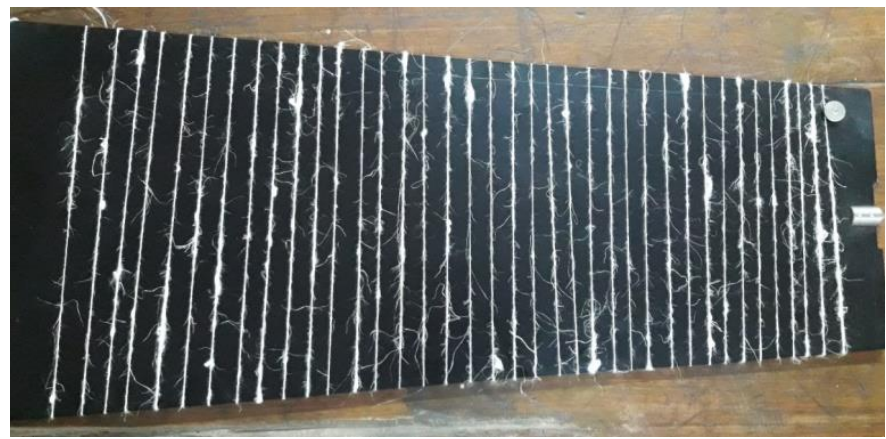

Figure 5.6: Hairiness

\subsection{Reason of such faults:}

The reasons for such faults lie within the drafting zone. If the drafting zone is not sufficiently appropriate for controlling the fibers in the drafting zone such faults occur. The gauge of the jute drafting zone is significantly higher than that of our polyester. As a result of that a paramount amount of polyester fibers are left floating in the drafting zone. This results in irregular distribution of polyester throughout the sliver when draft is applied. At some places there are more polyester fibers present as a clump whereas at some places there are no polyester fibers at all. This effects at the end product reducing the strength of the blended yarn as this thick places are not twisted enough to give desired strength and consequently thin places also occur and reduce the overall strength of the yarn. Ultimately this also results in variation in twist and count throughout the yarn. If we can distribute polyester fibers evenly through the sliver in draw frame better results could be achieved.

Delivery Zone

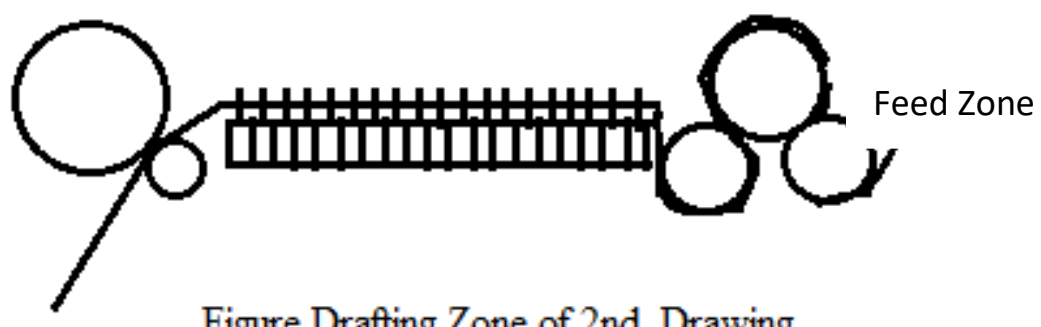

Figure Drafting Zone of 2nd Drawing 
Through this project we have experienced a whole new view of how blending of jute $\&$ polyester is operated on the basis of their properties. We have learned whether the end product produced shows better results in case of physical properties than when they are used individually or separately. The study is significant in the sense that it enables us to explore another area for jute which is available in ample in our countries. We hope that our project work will be helpful for further study and research activities.

\section{REFERENCE}

[1] Jute Fibre to Yarn By R. R. Atkinson, ATI

[2] Effect of glycerine \& alkaline hydrolysis on polyester fabric properties

[3] By: Srinivasulu K

[4] Link: www.fibre2fashion.com

[5] Study on the Physical Properties of Jute-Cotton Blended Rotor Yarn

[6] (Submitted: July 18, 2012; Accepted for Publication: November 29, 2012)

[7] Md. Abdus Shahid, Farid Ahmed and A.K.M. Mahabubuzzaman

[8] Performance of Jute Viscose/Polyester and Cotton Blended: Yarns for Apparel Use

[9] Shikha Bhardwaj and Shalini Juneja

[10] Investigation of the Physical Properties of Jute Blended Yarn Using a Novel Approach in Spinning Process

[11] Md. Abdus Shahid1, A. K. M. Mahabubuzzaman2, Farid Ahmed3, Ayub Ali4

[12] Link: http://creativecommons.org/licenses/by/4.0/

[13] Principle of Textile Testing, $3^{\text {rd }}$ Edition, JE BOOTH, ISBN:81-239-0515-7 